\title{
FAIR PLAY: SUS ORÍGENES Y SIGNIFICADOS EN EL DEPORTE Y LA SOCIEDAD ${ }^{1}$
}

\author{
Roland Renson \\ Faculty of Kinesiology and Rehabilitation Sciences, \\ Ku Leuven (Bélgica) \\ roland.renson@kuleuven.be \\ Traductor: Francisco Ferrara ${ }^{2}$ \\ Instituto Superior de Formación Docente $n .^{\circ} 84$, \\ Mar del Plata (Argentina) \\ franferrara@live.com.ar
}

Fecha de recepción: Noviembre 2018

Fecha de aceptación: Febrero 2019

http://doi.org/10.15366/citius2019.12.1.001

\section{Resumen:}

El deporte moderno se originó en Gran Bretaña como un producto cultural de la modernidad haciendo énfasis en la igualdad y la competencia. El ideal de fair play fue el credo moral de este nuevo espíritu deportivo, creado en el siglo XIX por la clase alta y media alta inglesa. El deporte moderno se forjó en las Public Schools de élite, tales como Eton y Rugby, donde el «autogobierno» era la innovación pedagógica del momento mientras reinaba la ideología Spencereana de la «supervivencia del más apto». La tesis aquí presentada desarrolla la idea de que el fair play se sostuvo por el simple hecho de sobrevivir a aquellos juegos violentos que gradualmente fueron estandarizados y codificados. La novela de Thomas Hughes, Tom Brown's schooldays, diseminó el nuevo credo deportivo, convirtiendo a este último y a su director, Thomas Arnold de la Rugby School, en modelos a seguir que inspiraron a toda una generación, incluido Pierre de Coubertin. El fair play fue el lema del gentleman inglés amateur y el mismo se puso bajo presión cuando el rugby y el futbol se extendieron a las clases trabajadoras. Los jugadores profesionales eran considerados, por los defensores del amateurismo, como aquellos que echaban a perder el juego por no jugar por el juego mismo. La pregunta es, si el fair play se ha convertido en un sobreviviente anacrónico del viejo ideal amateur y si la escena deportiva profesional posmoderna - como una rama legítima del mundo del espectáculo- debería guiarse por un código de ética profesional.

Palabras claves: Fair play, deporte moderno, apuestas, Public Schools, espíritu deportivo, amateurismo, profesionalismo.

\section{Title: FAIR PLAY: ORIGIN AND MEANINGS IN SPORT AND SOCIETY}

\author{
Abstract: \\ Modern sport originated in Great Britain as a cultural product of modernity, emphasizing equality \\ and competition. Fair play was the moral creed of the new sporting ethos, created by $19^{\text {th }}$ century upper and

\footnotetext{
${ }^{1}$ Una versión de este artículo en inglés se publicó en el año 2009 en la revista Kinesiology de la Universidad de Zagreb, en su número 41 (2), pp. 5-18, bajo la autoría de Roland Renson. Esta nueva publicación ha sido traducida y adaptada por Francisco Ferrara.

${ }^{2}$ Se ha hecho constar el nombre del traductor a petición de Roland Renson.
} 
upper-middle class Englishmen. Modern sports were forged in elite Public Schools such as Eton and Rugby, where self-government was a pedagogical innovation and where Spencer's 'survival of the fittest' was part of the ideology. The thesis presented here is that fair play was advocated for the simple sake of survival in these rough games, which were gradually standardized and coded. Thomas Hughes' novel Tom Brown's schooldays disseminated the new sports creed and Tom Brown and his headmaster Thomas Arnold of Rugby School became role models, who inspired a whole generation, including Pierre de Coubertin. Fair play was the watchword of the gentleman amateur and the notion came under pressure when rugby and Association football were spread to the working classes. Professional players were considered by the defenders of amateurism as spoilsports, who no longer played the game for the game's sake. The question is asked whether fair play has become an anachronistic survival of the old amateur ideal and whether the postmodern professional sport scene - as a legitimate branch of show business - should be guided by a code of professional ethics?

Key words: Fair play, modern sport, betting, public schools, sport ethos, amateurism, professionalism.

\section{Introducción}

Fair play es un concepto mundialmente entendido que encontró sus orígenes en el deporte. No solo es un elemento esencial del mismo, sino que también se ha convertido en una filosofía más general de respeto por los demás y por las reglas, ya sea en el ámbito deportivo o en el de los negocios. Publicaciones como la de Sigmund Loland, Fair play in sport: a moral norm system (Fair play en el deporte: un sistema de normas morales, 2002), más la creación de una amplia gama de comités nacionales e internacionales de fair play, trofeos y premios, subraya la relevancia e importancia del juego limpio para el deporte y la sociedad. Este artículo de revisión examina los orígenes de la noción de fair play y lo relaciona con los orígenes del deporte moderno en Gran Bretaña.

Las formas tradicionales de juegos y actividades recreativas de la Inglaterra pre-industrial a menudo estaban vinculadas al calendario eclesiástico y tenían un carácter altamente ritualizado. Estos certámenes físicos tradicionales eran, muchas veces, caóticos y de una naturaleza violenta, en donde las reglas variaban ampliamente de un lugar a otro, evidenciándose al enfrentarse jugadores de diferentes pueblos cercanos o barrios de la misma ciudad. Un ejemplo vivo de dichos juegos brutales es el partido anual de futbol de Shrovetide, en el pueblo de Ashbourne (Inglaterra). Recientemente, Hugh Hornby ha dado una excelente descripción de las quince formas aún existentes del llamado «festival football» en su libro Uppies and downies: the extraordinary football games of Britain (2008).

El deporte moderno, por el contrario, se caracteriza por un enfoque más racional y ordenado. Se ha llegado a un consenso en torno a que el mismo se forjó en los campos de juego de las Public Schools británicas durante los siglos XVIII y XIX. Sin embargo, recientemente, algunos historiadores del deporte han desafiado la idea de que, tanto del fútbol como del rugby, se originaron exclusivamente en las escuelas públicas inglesas (Inglis, 2008).

El deporte moderno puede ser definido como:

«Actividades físicas de carácter recreativo y competitivo, en las cuales se trata de superar las propias limitaciones físicas (el lema olímpico postula: 'citius, altius, fortius '3) o un obstáculo externo

\footnotetext{
${ }^{3}$ «Más rápido, más alto, más fuerte».

Citius, Altius, Fortius Volumen 12 ne 1. Mayo, 2019. ISNN. 2340-9886.

http://doi.org//10.15366/eitius2019.12.1
} 
(ya sea un oponente, o un obstáculo natural) de acuerdo con un código de conducta previamente acordado (fair play, reglas, etc.)»(Renson, 1980, p. 16)

El fair play, o juego limpio, se originó en Gran Bretaña como parte de este nuevo espíritu deportivo y desde allí se exportó a toda Europa y el mundo.

La primera generación europea de fanáticos del deporte, como Pierre de Coubertin en Francia, estaba fascinada con esta nueva forma de vida deportiva que percibió, al mismo tiempo, como una nueva forma de moralidad práctica. En su trabajo publicado en 1897 bajo el llamativo título, «¿A quoi tient la supériorité des anglo-saxons?» («¿Cuál es la superioridad de los anglosajones?»), Edmond Demolins escribió:

«Incluso cuando no está trabajando, el inglés tiene la necesidad de esforzarse: ya sea practicando canotaje, jugando al cricket o al fútbol. Realizará un difícil y peligroso ascenso por la simple razón de haber superado una dificultad (p. 373)».

Otro autor anglófilo, el alemán Rudolf Kircher, escribió en 1927 un libro titulado «Fair Play: Sport Spiel und Geist in England» («Juego limpio: deporte y espíritu en Inglaterra»), en el que afirmó que uno no puede entender el deporte moderno y su espíritu de juego limpio sin entender el contexto global de la sociedad inglesa:

«El deporte es jugar, pero el concepto de 'jugar' (play) se extiende mucho más allá del dominio del deporte [...] El espíritu de juego, entre los ingleses, se expresa no solo en los juegos más físicos, sino que penetra profundamente en la vida y cultura de toda la nación [...] Si uno destruye el espíritu de juego de los ingleses, destruye al mismo tiempo, el espíritu de toda una nación (pp. 11-17)».

Este tema fue retomado por Hans Indorf en su trabajo de 1938 llamado «Fair Play und der Englische Sportgeist» («Fair Play y deportividad inglesa»), en donde una vez más, el fair play era visto como parte de la idiosincrasia de la sociedad inglesa.

\section{2. ¿Qué es, en una palabra?}

La palabra fair proviene del inglés antiguo faeger, similar al alto alemán antiguo fagar que significa hermoso, bello. La palabra play deriva del inglés antiguo plega, similar a plegian, que significa to play. El inglés play, to play, es equivalente al antiguo alto alemán pflegan y al holandés medio pleyen. El verbo holandés plegen, comprometerse, y el alemán pflegen aún existen, pero la palabra holandesa para play es spel, con su verbo spelen, relacionado con el término alemán Spiel y el verbo spielen (Gillmeister, 1993).

La palabra game proviene del inglés antiguo gamen, similar al viejo alto alemán gaman, que significa diversión, entretenimiento. Dicho término ha sobrevivido en el backgammon, un juego en el que las piezas, a veces, son forzadas a retroceder. La palabra game también pude referirse a aquellos animales que son cazados por deporte o comida. En este punto sería interesante observar cómo ambos significados del término game están interconectados, ya que en Gran Bretaña existe la llamada «Game Laws». ${ }^{4} \mathrm{Al}$ analizarlas, vemos que conciernen a los derechos y controles legales que existen con respecto a una variedad de animales. No hay una definición general de game, mejor dicho, podemos decir que ha sido definido según una serie de leyes del Parlamento. Por ejemplo, la Game Act, o Ley de caza, de 1831, incluía la caza de liebres, faisanes, perdices y aves silvestres.

\footnotetext{
${ }^{4}$ El equivalente a la «Ley de Caza» argentina.
} 
Los ciervos se agregaron a los efectos de la Game Licences Act (Ley de Licencias) en 1860, mientras que las liebres y los conejos se definieron como caza de tierra. Por otro lado, no existen derechos de propiedad absolutos sobre animales salvajes vivos como zorros, tejones, linces, etc. (Collins, Martin y Vamplew, 2005, p.132). Si observamos las clásicas enciclopedias deportivas de la Belle Epoque, como por ejemplo The encyclopaedia of sport \& games, editada por el Conde de Suffolk y Berkshire en 1911 y presentada en cuatro volúmenes, encontraremos que entre el 70 y el $80 \%$ de las entradas se refieren a todo tipo de animales que pueden ser cazados, no solo en Europa sino en el mundo. Incluso en un deporte «sangriento» como la caza, los principios del fair play fueron respetados y se hizo una distinción entre la caza justa (abierto a la persecución legítima) y el juego prohibido, o, mejor dicho, caza prohibida.

\section{El desarrollo del deporte moderno}

Historiadores deportivos como Manfred Lämmer, Ingomar Weiler, David Young y muchos otros, han disipado el mito de que los antiguos griegos fueron los inventores del fair play. El arqueólogo e historiador francés, Paul Veyne (citado en Weiler, 1991, p. 55), expresó que el concepto de jugar, dentro de un conjunto predefinido de reglas, es decir, dentro de la lógica de un juego, parece ser una invención anglosajona, mientras que los juegos antiguos intentaban imitar la brutal realidad de la guerra en lugar de tratar de respetar un conjunto de reglas ficticias.

Sociólogos deportivos, como Eric Dunning y Nobert Elias, han ayudado a disipar el mito del juego limpio de los «maestros antiguos»:

«Los deportes griegos de la antigüedad estaban basados en un espíritu guerrero que implicaba tradiciones de honor en lugar de equidad» (Dunning, 1971, p. 83).

«Los boxeadores de Olimpia no eran categorizados por peso más que los luchadores» (Elias, 1971, p. 102).

Pueden encontrarse rastros de una preocupación moral por el juego y el jugar entre los humanistas renacentistas como Desiderio Erasmus y Juan Luis Vives, colegas en el famoso Colegio Trilingüe de Lovaina. El erudito español Vives quedó profundamente conmocionado por la violencia de su tiempo y desaprobó, por ejemplo, los juegos que se utilizaban para el entrenamiento militar. Además, en 1538, publicó Linguae Latinae exercitatio, más conocido como Los Diálogos, en donde estableció sus «Seis leyes del juego», ${ }^{5}$ exponiendo en su quinta Ley lo siguiente:

«Ningún juego debería servir para provocar la ira entre jugadores, y al mismo tiempo los jugadores participantes deben, durante todo el juego, ser compañeros, darse ánimo, sentir placer y alegría, mientras que no debe haber ningún rastro de engaño, sordidez o avaricia» (citado en Renson, 1976, p. 9).

\footnotetext{
${ }^{5}$ Las seis reglas eran:

1- Quando Ludendum? El tiempo de juego.

2- Cum Quibus Ludendum? Compañeros de juego.

3- Quo Ludo? Tipo de juego.

4- Qua Sponsione? Qué y cuanto se apuesta.

5- Quemadmodum? La manera de jugar.

6- Quamdiu Ludendum? Tiempo de juego.
} 
Por otro lado, Peter McIntosh, en su obra pionera Fair play: ethics in sport and education (1979, pp. 20-21), señaló que Richard Mulcaster, director de la Merchant Taylor's School de Londres de 1560 a 1586, pensaba que el futbol podía responder a propósitos educativos y morales.

En su libro Homo ludens (1938, p. 12), el filósofo holandés Johan Huizinga escribió críticamente sobre la noción de juego y jugar en el deporte contemporáneo y sobre su origen:

«Aunque los seres humanos se han permitido tales actividades [concursos físicos] desde el comienzo de los tiempos, estos solo adoptan el carácter de juegos organizados en un grado muy leve ... Hay, sin embargo, otras formas de concursos que se desarrollan en 'deportes' ... Que este proceso comenzó en Inglaterra en el siglo XIX es comprensible ... La estructura de la vida social inglesa tenía mucho que ver con eso. El autogobierno local alentó el espíritu de asociación y solidaridad, ... la ausencia de entrenamiento militar obligatorio, ... la forma peculiar de educación ..., y finalmente la geografía del país ... Así, Inglaterra se convirtió en el cuna y foco de la vida deportiva moderna.»

\section{De las apuestas a la justicia («fairness»): el deporte moderno como metáfora de la igualdad}

El sociólogo Norbert Elias (1971, p. 101), padre de la teoría de la civilización, ha demostrado que el énfasis especial en el disfrute de los juegos y contiendas, junto con la tensión y excitación que éstos crean, estaban en cierto punto conectados con el goce por las apuestas. También expresó que dichas apuestas jugaron un papel considerablemente importante, tanto en la transformación de las formas más «vulgares» de los juegos en los deportes, como en el desarrollo del carácter distintivo de jugar de una manera justa en Inglaterra. Peter McIntosh $(1979$, p. 2) ha afirmado acertadamente que el ser justo (fairness) es una idea y, quizás, un ideal que se encuentra implícito y explícitamente presente en las relaciones humanas. Las expresiones comentario justo (fair comment), precio justo (fair price), acuerdo justo (fair trade), indican que el concepto de ser justo no solo se confina al deporte y al fair play. Además, «ser justo está relacionado con la justicia, y la justicia es fundamental... para la supervivencia de la especie humana».

En un ensayo muy original titulado Sport as a symbolic dialogue (El deporte como un diálogo simbólico), su autor, C.E. Ashworth, presentó la tesis de que, si la vida puede considerarse un concurso, en el que las identidades se establecen, prueban y posiblemente incluso se abandonan, los juegos pueden pensarse como una forma idealizada de vida social. Los juegos de competencia, a través de sus reglas, constituyen una identidad con una seguridad consensuada que en la vida misma no siempre es posible. Por lo tanto, Ashworth (1971, p. 45), consideraba el deporte como un lenguaje simbólico: «El hombre moderno insiste en la igualdad en el deporte, es decir, en estrictas reglas formales que hacen que los factores que van más allá de las habilidades y capacidades individuales sean iguales para todos. Esto se debe a que él se define como igual».

La igualdad es también la segunda de las siete características fundamentales del deporte moderno identificadas por Allen Guttmann en su obra From ritual to record: the nature of modern sport (1978). Las siete características de Guttmann son el secularismo, el principio de igualdad, la especialización, la racionalización, la burocratización, la cuantificación, y los récords. El principio de igualdad implica que todos deberían, teóricamente, tener la oportunidad de competir, y que las condiciones en la competición deberían ser las mismas para todos los participantes. La igualdad de oportunidades (al comienzo de la competición) no solo es un principio democrático, sino también, un factor necesario en el aumento de la emoción, haciendo que las apuestas sean una actividad que valga la pena - aunque el resultado sea imprevisible. Esta llamada «igualdad de oportunidades» incluso se aplicó absurdamente en la caza de zorros. Elias (1986, p. 168) creía que sin un arreglo 
«justo» (fair), el placer y la emoción provocada por la tensión de la lucha, que era y sigue siendo el principal propósito del deporte de caza de zorros, sería muy corta. Sin embargo, el deporte dio lugar a controversias entre los que ponían mayor énfasis en la caza misma (en el proceso de caza) y aquellos que ponían más energía y acento en matar al zorro (los resultados), es decir, entre los defensores del «jugar bien» y los defensores del «conseguir la victoria». «Sin una forma capaz de mantener por un tiempo el inestable equilibrio de oportunidades entre los oponentes, uno no podía esperar un 'buen juego'...».

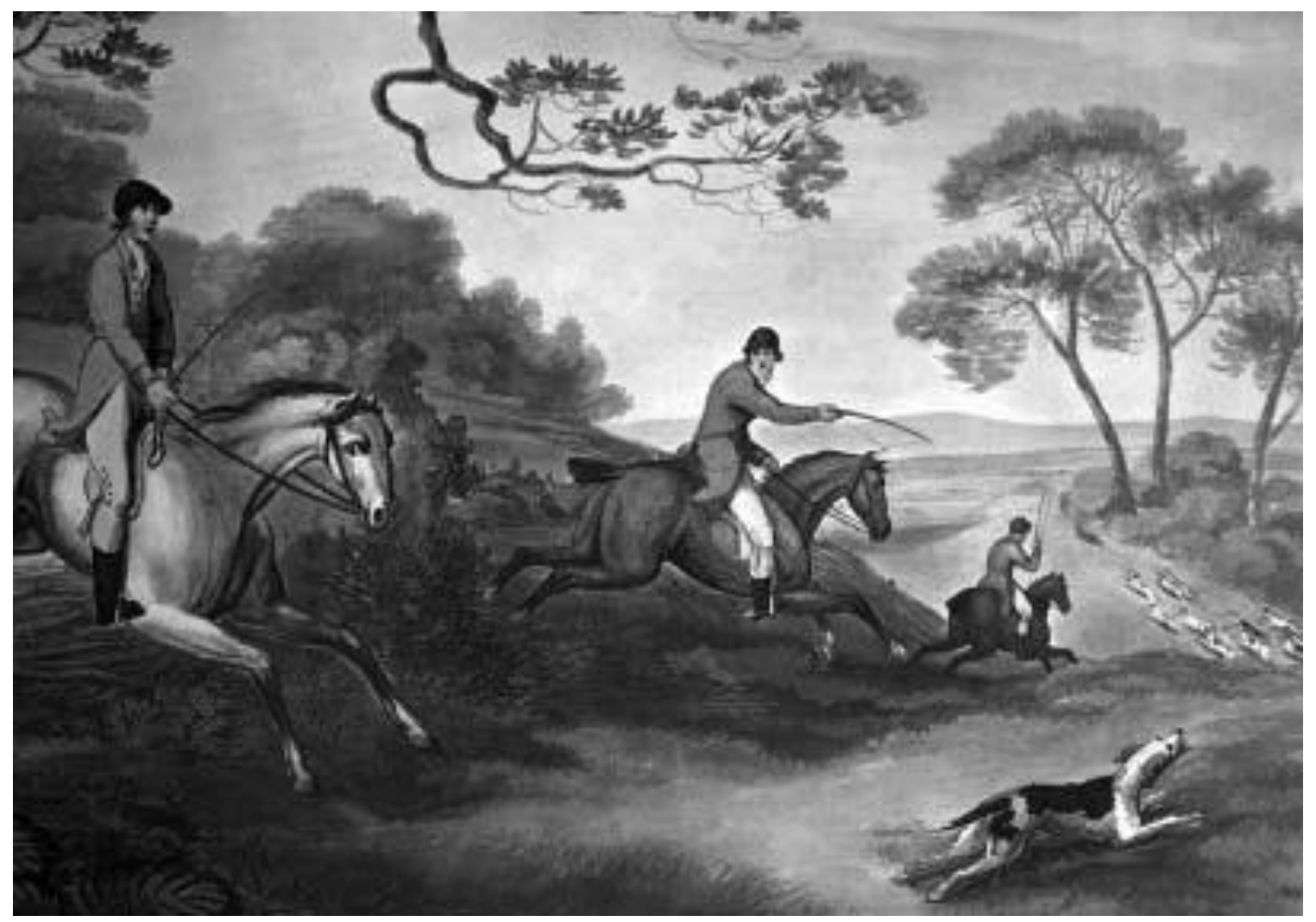

La imagen muestra una cacería de zorros en una pintura estampada por Vivares y Merke. Publicado el 20 de enero de 1808 por Edward Orme, Londres.

Sin embargo, parece que el principio de crear bandos iguales, así como alguna forma incipiente de especialización y cierto control de la violencia, ya se había introducido en el futbol antes del siglo XVIII y de la Ilustración. En el libro de juegos de Francis Willoughby, «A seventeenth century treatise on sports, games and pastimes», que fue re-editado en 2003, se puede leer:

«Los jugadores se dividen por igual de acuerdo a su fuerza y agilidad... Por lo general, dejan algunos de sus mejores jugadores para proteger el arco mientras que el resto sigue el balón... A menudo se fracturan las tibias al chocar en busca de la pelota, por lo que se creó la regla de no poder golpear por encima del nivel de la pelota». (p. 168)

Además, se introdujo el principio de hándicap en los deportes como las carreras de caballo, el golf e incluso, el tenis, para garantizar un equilibrio de oportunidades entre competidores de diferentes pesos y niveles de juego. Originalmente, hand in cap era el nombre de un juego de 
negociación que involucraba a dos jugadores y una especie de árbitro. Un ejemplo típico del siglo XIV podía incluir el intercambio de una capa por una capucha. El árbitro decidía acerca de la diferencia en el valor entre los dos objetos intercambiados. Ambos jugadores colocan sus manos dentro de una bolsa y deberán sacarlas al mismo tiempo. Una mano abierta significaba un acuerdo para comerciar y una mano cerrada era una negativa. Alrededor de 1750, el término hándicap comenzó a aplicarse a las carreras de caballos (The Oxford English Dictionary, 1989, Crowley \& Crowley 1999).

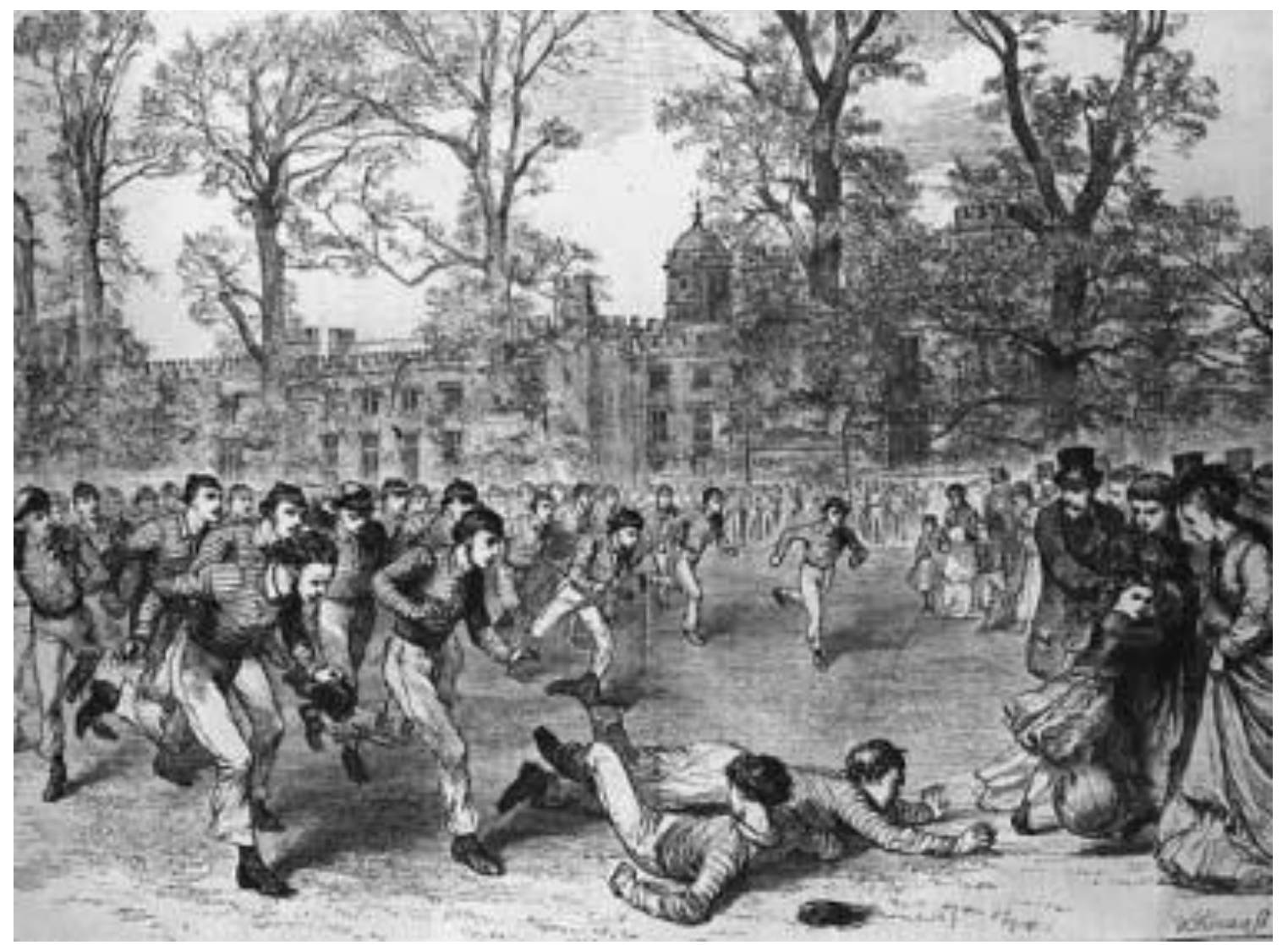

El Rugby College, donde se originó el Rugby, se convirtió en un lugar mítico. Pierre de Coubertin santificó a Thomas Arnold, el director de dicha escuela, como el «padre del deporte moderno». Dibujado por W. Thomas, 1870.

Allen Guttmann, que ha analizado a fondo la naturaleza del deporte moderno, ha subrayado que la modernidad fue clara en el camino de crear igualdad de condiciones en las competiciones, un impulso que se llevó al extremo en Francia. En algunas pistas y eventos, los atletas estaban clasificados por su edad; los corredores de mayor edad comenzaban detrás de los más jóvenes en la línea de largada, un metro por cada 6 meses después de los 16 años. Como decía Guttmann, «este experimento de igualdad ahora parece extraño, pero el hándicap basado en el peso aún funciona en las carreras de caballos». Guttmann, A. (2004, p. 98), 


\section{5. «Ser un buen animal»: el deporte moderno como metáfora de la competencia}

En 1860, el filósofo británico Herbert Spencer publicó una pequeña monografía titulada «Educación: intelectual, moral y física», en la que se puede encontrar la siguiente cita:

«Las personas están empezando a ver que el primer requisito para tener éxito en la vida es 'ser un buen animal', y ser una nación de buenos animales es la primera condición para la prosperidad nacional».

Mientras que Ashworth vio al deporte moderno como una metáfora de la igualdad, Richard Holt $(1989$, p. 97) ha demostrado que el deporte también sirvió como metáfora de la competencia en el periodo en que Britania gobernó gran parte del mundo. Dicha ideología competitiva, junto a la «supervivencia del más apto», se desarrolló fuertemente a mediados del siglo XIX mientras que los productos británicos conquistaron el mercado mundial. El deporte de alguna manera protegió la ética de la competencia, o más precisamente, la ética de una competencia justa y ética, por la cual los británicos prosperaron:

«La disminución de la importancia de ganar los juegos en favor de la de tomar parte en ellos, favoreció el ímpetu que recibió la participación generalizada y la idea de la vida como una lucha permanente. Al enseñarles a los chicos cómo perder, y así también, como ganar con dignidad, se fortaleció el principio competitivo más amplio» (Holt, 1989, p. 97).

El marco de reglas, incluidas aquellas que aseguraban justicia, e igualdad de oportunidades de ganar para todos los participantes, se volvió más estricto. De esta manera, las reglas se volvieron más precisas y la supervisión de éstas más eficiente, por lo que las penas por violarlas se volvieron más difíciles de evadir (Elias, 1986, p.151). J.E.C Weldon, director de la Escuela de Harrow (18811895), lo expresó de manera muy explícita:

«Es mi deseo más sincero que los juegos atléticos se mantengan puros de todo lo que pueda hacer disminuir el espíritu de juego. Porque la lección de fair play en el deporte es la lección de honestidad en los negocios...» (citado por Mangan, 1998, p. 37).

El historiador del deporte James Anthony Mangan vinculó con claridad la relación entre la ética de juego y el imperialismo británico, proporcionando muchos ejemplos, entre ellos, una cita del artículo de John Astley Cooper publicado en 1916 en el periódico United Empire y titulado: «The British imperial spirit of sport and war» («El espíritu imperial británico del deporte y la guerra»). La guerra, según Cooper, era una «cruzada muscular cristiana», en la que el Imperio era la «Tierra Santa», que no había que re-conquistar, sino que debía ser preservada. Exultante, Cooper esperaba que cuando las tradiciones deportivas de la gente temblaran en la balanza, «el instinto innato del fair play pasará a ser primordial». Un verdadero deportista detesta al bravucón y la cultura alemana es la antípoda del espíritu deportivo imperial británico» (citado por Mangan, 1998, p. 55).

\section{Las Public Schools y el deporte moderno}

Eric Dunning (1971, p. 134), al estudiar los factores sociales que han contribuido al desarrollo del fútbol moderno, señaló que desde la segunda mitad del siglo XVIII las formas tradicionales de fútbol comenzaron a declinar gradualmente como consecuencia de la creciente industrialización y urbanización. Al mismo tiempo, nuevos modelos de juego, más acordes a la sociedad de entonces, estaban comenzando a emerger en las Public Schools. 
Está ampliamente aceptado que el deporte moderno se forjó en estas Escuelas Públicas de élite inglesas, donde el autogobierno fue una innovación pedagógica y en donde las actitudes de fair play y conductas caballerescas hicieron disminuir la violencia tolerada en los campos de juego. «Jugar el juego por el bien del juego mismo» era el reflejo de la elite y del ethos del verdadero «amateurismo». "Jugar de una manera justa por el bien de la supervivencia» es una declaración que me gustaría hacer para poder explicar la naturaleza instrumental o funcional del ethos del fair play. Las lesiones eran aún comunes es los partidos de fútbol de las Public Schools a lo largo del siglo XIX, especialmente las fracturas de tibias, debidas a los fuertes cruces entre los rivales que utilizaban un calzado de cuero con capuchón de hierro -botas de cuero que utilizaban originalmente quienes cavaban canales y después los trabajadores del ferrocarril-. Sin embargo, el componente de la «pelea ficticia» fue gradualmente desplazando al de la «pelea real». El fútbol comenzó a convertirse en un certamen grupal que proporcionaba, en la medida de lo posible, el placer de una pelea verdadera, pero sin sus riesgos y peligros (Dunning, 1971, p. 144). El tutor de Dunning, Norbert Elias, describió el deporte como «certámenes que implican alcanzar un esfuerzo muscular de un nivel, orden y autodisciplina jamás antes alcanzado» (Elias, N.,1986, p. 1951). Al mismo tiempo, sin embargo, estos deportes llegaron para incorporar una serie de reglas que aseguraban un balance entre lograr una alta tensión de combate y una protección razonable de las lesiones. En el siglo XIX eran los propios chicos los responsables de administrar y dirigir sus propios partidos de futbol, ya que la mayoría de los maestros eran indiferentes u hostiles al juego. Con su espíritu de auto-gobierno, los conflictos debían ser resueltos entre los propios jugadores: «[...] los jugadores, a través de sus capitanes, resolvían tales diferencias - en el fútbol, el árbitro apareció tarde en el campo de juego y no se le dio un silbato hasta 1891» (McIntosh, 1979, p. 118).

Thomas Arnold, director del Rugby College de 1828 a 1842, fue a menudo representado - e incluso idolatrado por Pierre de Coubertin - como el principal agente de la reforma escolar inglesa y como la persona que pudo manejar la crisis endémica de la violencia entre los estudiantes. Sin embargo, no fue Thomas Arnold quien advirtió la influencia de la moral deportiva, sino uno de sus maestros asistentes, G.E.L. Cotton, quien se convirtió en el director del Marlborough College en 1852 (McIntosh, 1979, p. 27). En la ya mencionada novela de Thomas Hughes Tom Brown's schooldays (1857), Tom y alguno de sus compañeros de escuela estaban debatiendo sobre cricket con un joven maestro, que se cree que está basado en Cotton, quien les explica la «ideología» del juego:

«La disciplina y la confianza en el otro que enseña es muy valiosa [...] Debería ser un juego desinteresado. Disuelve lo individual en los once jugadores del equipo; él no juega para ganar, sino para que el que está a su lado pueda hacerlo» (p. 355).

Uno de los principios del Rugby School de Thomas Arnold era que el adulto responsable se desarrollaba a partir del niño responsable. Sin embargo, en su novela, Thomas Hughes supone que los juegos no tenían mucha influencia en Arnold como educador y que no formaba parte de su responsabilidad como director. Los juegos eran recreación y, por lo tanto, la exclusiva prerrogativa de los jóvenes. De acuerdo con la novela, todos los aspectos del deporte son asuntos individuales, de equipo o casas. Los directores tienen un interés benevolente, ofreciendo consejos, pero nunca organización (Sanders, 1989, p. XII-XIII).

\section{El fantasma de Tom Brown}

Tom Brown se convirtió en un héroe victoriano y en un modelo a seguir para aquellos chicos que atravesaban la lucha de la adolescencia. Rugby se convirtió en un lugar mítico, donde no 
solo se originó el deporte que lleva su nombre, sino también en un lugar de peregrinación para Pierre de Coubertin quien santificó a Thomas Arnold como el «padre del deporte moderno» (MacAloon, 1981).

Otros han sido menos clementes con respecto a la novela de Hughes. Richard Usborne (1977), por ejemplo, en su ensayo titulado «La sombra de Tom Brown» sostuvo que el libro citado se encargó de grabar en la clase dominante inglesa dos creencias irracionales. Primeramente, que el castigo corporal debía ser valientemente recibido por el varón (acoso, azotes, peleas escolares, «ir fuerte» en los juegos, morder, quebrar el cuello en el campo de caza, heridas o muerte en batallas defendiendo a tu país). En segundo lugar, que el castigo corporal debía ser fuertemente infligido cuando era sancionado por una autoridad e incluso, algunas veces, cuando no era sancionado por ella (niños golpeados por sus padres o tutores, preceptores o directores, golpear durante el scrum (melé) sin ser visto por el árbitro, aplicar la pena capital siendo juez o verdugo, y en la guerra, admitir bajas, preferentemente del enemigo, pero de los propios hombres si fuese necesario). George MacDonald Fraser (1977) enfatizó que el código de honor de las Public Schools puede operar solo verdaderamente en esa sociedad cerrada y delimitada, y que los alumnos actúan con sentido común, sabiendo cuándo es suficiente.

La misma aura mítica se cierne alrededor de Eton School, el lugar donde nació la Asociación de Fútbol. Mientras caminaba por los campos de juego, el Duque de Wellington habría dicho: «Fue aquí donde se ganó la batalla de Waterloo» (McIntosh, 1979, p. 34). La realidad fue menos idílica: El Duque estuvo en Eton, pero no le gustaba la escuela. Además, no había juegos obligatorios en «su» Eton, y el duque no sabía absolutamente nada de los campos de juego cuando visitó su antigua escuela. Lo que realmente dijo fue: «Realmente creo que le debo mi espíritu de trabajo a los trucos que usaba para jugar en el jardín». Paul Johnson (1977, pp. 14-15) ha señalado que una cosa es demoler la mitología, y otra cosa es hacer una estimación justa de la influencia que las escuelas públicas han ejercido, y todavía ejercen, en la vida pública. Anthony Storr, psiquiatra, planteó el mismo punto: « ¿El sistema de escuelas públicas promueven un crecimiento que apunta a la salud psicológica y a la madurez, o produce 'niños mayores que nunca crecen?» (Storr, A.,1977, p.98),

Me gustaría llamar la atención sobre el hecho de que «Tom Browns's schooldays" ha generado cientos de novelas escolares en las que encontraremos el cricket, el fútbol y otros deportes, no solo en Gran Bretaña, sino también en los Estados Unidos, donde el jesuita Francis Finn (1859-1928) creó su propia versión católica del fair play y el abordaje de la vida en internado. Tanto las virtudes educativas como los peligrosos vicios relacionados a las prácticas de estos juegos se expresan en populares novelas de Francis Finn, tales como «Tom Play-fair», «Percy Wynn», «Claude Lightfoot», «Harry Dee» y «That football game». Estos libros también fueron apreciados por jóvenes europeos de la generación de mi padre (cuyas copias aún tengo) y fueron vistos como una versión católica de Muscular Christianity. ${ }^{6}$

\footnotetext{
${ }^{6}$ El Cristianismo muscular fue un movimiento filosófico que se originó en Inglaterra a mediados del siglo XIX, caracterizado por la creencia en el deber patriótico, la hombría, la belleza física y moral del atletismo, el trabajo en equipo, la disciplina, el autosacrificio y «la expulsión de todo lo considerado afeminado, no inglés y excesivamente intelectual».
} 


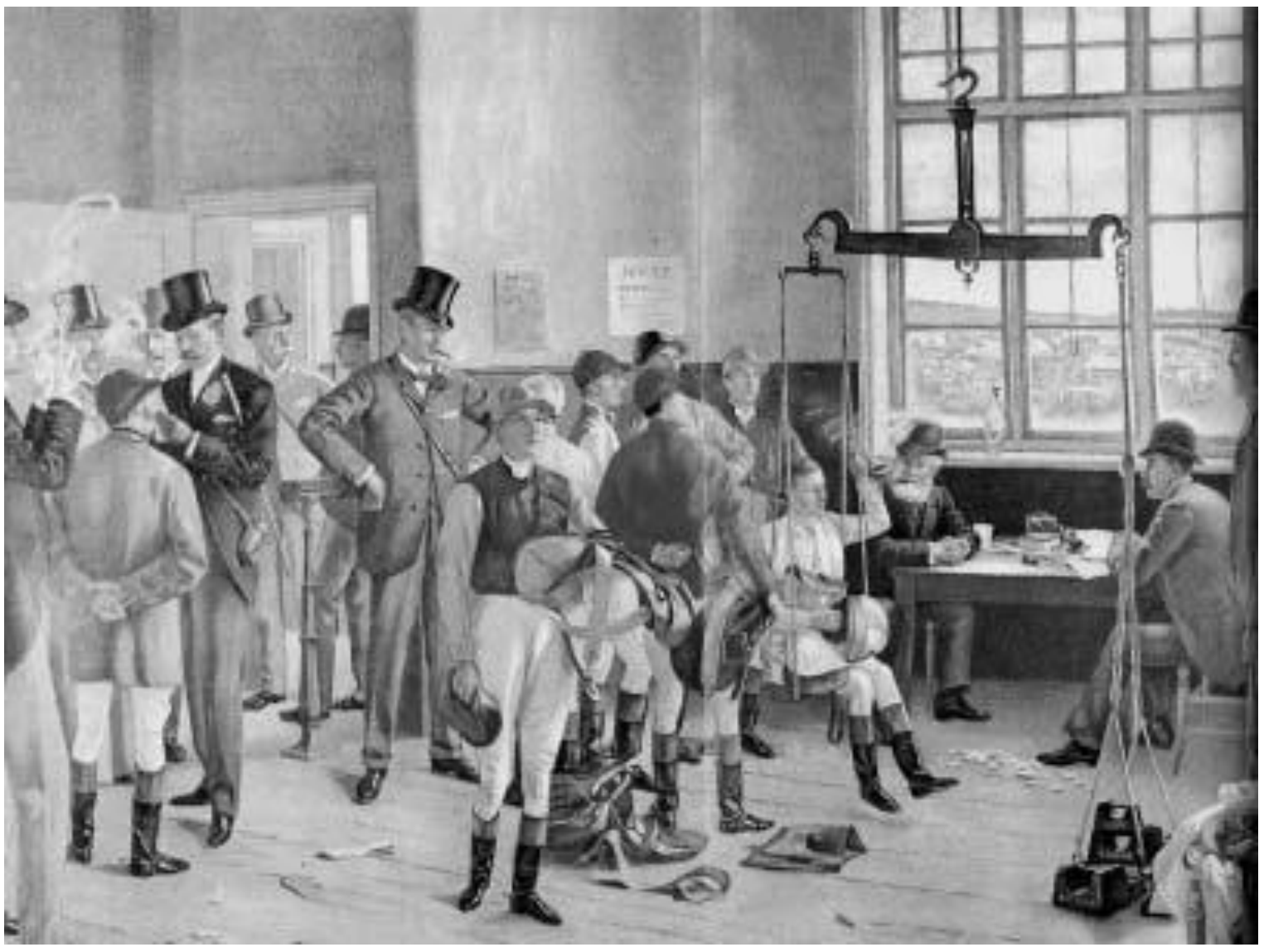

El principio de «hándicap» fue introducido en las carreras de caballos, y en otros deportes, para asegurar un equilibrio en las posibilidades entre competidores de diferentes categorías de peso. Esta imagen de «La habitación de peso», donde los jockeys eran pesados apareció en la revista Illustrated London News de 1893.

\section{De las Public Schools a las clases trabajadoras: amateurs vs. profesionales}

Debido al gran nivel de autonomía del cual disfrutaban los chicos, sus luchas por el poder dentro de las escuelas y el hecho de que, como monitores, se acostumbraban al ejercicio del poder en una temprana edad, muchos educadores estaban convencidos de que las escuelas públicas eran un campo de entrenamiento útil para los jóvenes miembros de su clase. Debido a su carácter civilizado y por la etiqueta de respetabilidad aceptada en las escuelas, hacia 1850 el futbol se había convertido en una actividad socialmente permitida para los jóvenes «gentlemen» (Dunning, 1971, pp.140,146).

En relación con esto, Norbert Elias (1986, p. 168) ha notado que este ethos no era el mismo que el de la clase media trabajadora, que era muy diferente al ethos de las clases ociosas, adineradas, sofisticadas y comparativamente refrenadas. En este contexto, la lucha de los amateurs por sobrevivir puede verse como la lucha de aquellos que vieron la noble herencia de sangre como su privilegio, contra aquellos cuyo «único honor era el de su propio mérito y sus propios actos». El primer punto de vista fue claramente expresado por el director del Radley College en 1849: 
«Un gentleman conoce y, al mismo tiempo, agradece, que Dios, en lugar de hacer a todos los hombres iguales, los haya hecho a todos muy desiguales...» (citado por Wigglesworth, 1996, pp. 87, $103)$.

Richard Holt $(1989,1992,2006)$ ha señalado que tales argumentos morales no eran más que peones en la lucha de clases deportiva entre gentlemen amateurs y profesionales de clase trabajadora. El argumento utilizado por la élite amateur era que, si el deporte era comercializado, entonces la victoria sería más importante que participar y, si esto sucediera, el juego ya no sería un encuentro amistoso, sino una lucha seria por puntos en un sistema de liga. Los equipos se convertirían en esclavos de sus seguidores, que estarían más interesados en el éxito que en el fair play. Holt (1989, p. 104) argumenta que esta visión de los sacerdotes del amateurismo victoriano fue buena y apropiada. Sin embargo, lo que no era aceptable era cómo estos valores se ponían en práctica: «el código amateur era en la práctica un medio para excluir a los jugadores de las clases trabajadoras de la competencia de alto nivel».

El fair play fue el lema del gentlemen amateur. El término «amateur» (aficionado) se ha convertido en la actualidad en «aquel que no juega por dinero», pero su significado original era más sutil. Fair play no solo significaba respetar las reglas del juego, sino también, cumplir con lo que generalmente se entiende como espíritu del juego. El deporte no solo debía jugarse con «buena fe», tenía que ser jugado con estilo de acuerdo con el eslogan «Lucha sin ira, arte sin malicia», como cantaron generaciones de Harrovians. Gradualmente se fue produciendo un cambio en la distinción original entre gentlemen y jugadores a la rígida distinción entre amateurs y profesionales. La nueva importancia de «cómo jugaste» le dio un significado adicional a la polémica cuestión del pago. El término «profesional» entró en uso en la década de 1850, mientras que el de «amateur», en 1880.

Antes de mediados del siglo XIX, los términos «gentlemen» y «jugadores» (players) eran usados principalmente en el crícket, para diferenciar a los que tenían recursos independientes y aquellos que no. Es decir, que originalmente, la distinción era pura y exclusivamente de posición social y no había deshonor alguno asociado a hacer dinero con el deporte (Holt, 1989, p. 103).

El famoso Corinthian Football Club, fundado en 1882, estaba originalmente determinado a jugar solo partidos amistosos contra otros clubes amateurs del área de Londres. Se negaron a unirse a la Football League 7 y a competir en la Football Association Cup, debido a que sus reglas originales les prohibían competir por cualquier copa o premio económico. También se negaron a realizar sanciones, inspirados en la idea de que dichas sanciones no formaban parte del espíritu de juego. Cuando finalmente decidieron formar parte de una competición oficial en 1900 vencieron al Aston Villa, campeones de La Liga, por 2 a 1 (Cavalini, 2007).

Los defensores del amateurismo también tenían otros motivos, ya que estaban convencidos de que el deporte debería ser un pasatiempo más que una vocación, condenando, incluso, la especialización (Guttmann, 2004, p. 98). Los verdaderos amateurs, que aún consideraban el entrenamiento y la competición como un pasatiempo, también pensaban que el entrenamiento intensivo conducía a una desigualdad en los términos de la competencia «cuando tuvieron que tomar sus lugares en la línea de partida junto a los trabajadores de tiempo completo» (McIntosh, 1979, p. 138).

\footnotetext{
${ }^{7}$ La English Football League es la competición de fútbol inglesa que se encuentra por debajo de la Premier League. La misma contiene tres divisiones, lo que sería equivalente a la «Primera B Nacional», a la «Primera C» $\mathrm{y}$ «Primera D» del futbol argentino.
}

Citius, Altius, Fortius Volumen 12 ne 1. Mayo, 2019. ISNN. 2340-9886.

http://doi.org//10.15366/eitius2019.12.1 
El uso del concepto «fairness» (justicia o, mejor dicho, en este caso, jugar de manera justa), derivado del deporte amateur, fue importante en todos los aspectos de la vida pública y activamente fomentado por las clases políticas predominantes (McKibbin, 1990, p. 22). Los sacerdotes que pregonaban el Cristianismo muscular y el Socialismo cristiano, muchos de los cuales fueron educados en las Public Schools, jugaron un papel central en la difusión del rugby y el fútbol entre las clases trabajadoras. Mientras que las clases medias-altas y altas insistían en la competencia individual en la esfera del trabajo, en la esfera del ocio enfatizaban el espíritu de equipo, el juego limpio y la cooperación: «Jugar por dinero era hacerlo funcionar». Pero, por desgracia, los clubes amateurs se vieron forzados a adoptar métodos de pago clandestinos para captar y retener a los jugadores de alto calibre «(...) 'shamateurismo"8 se convirtió en la norma». (Dunning, 1971, p. 149).

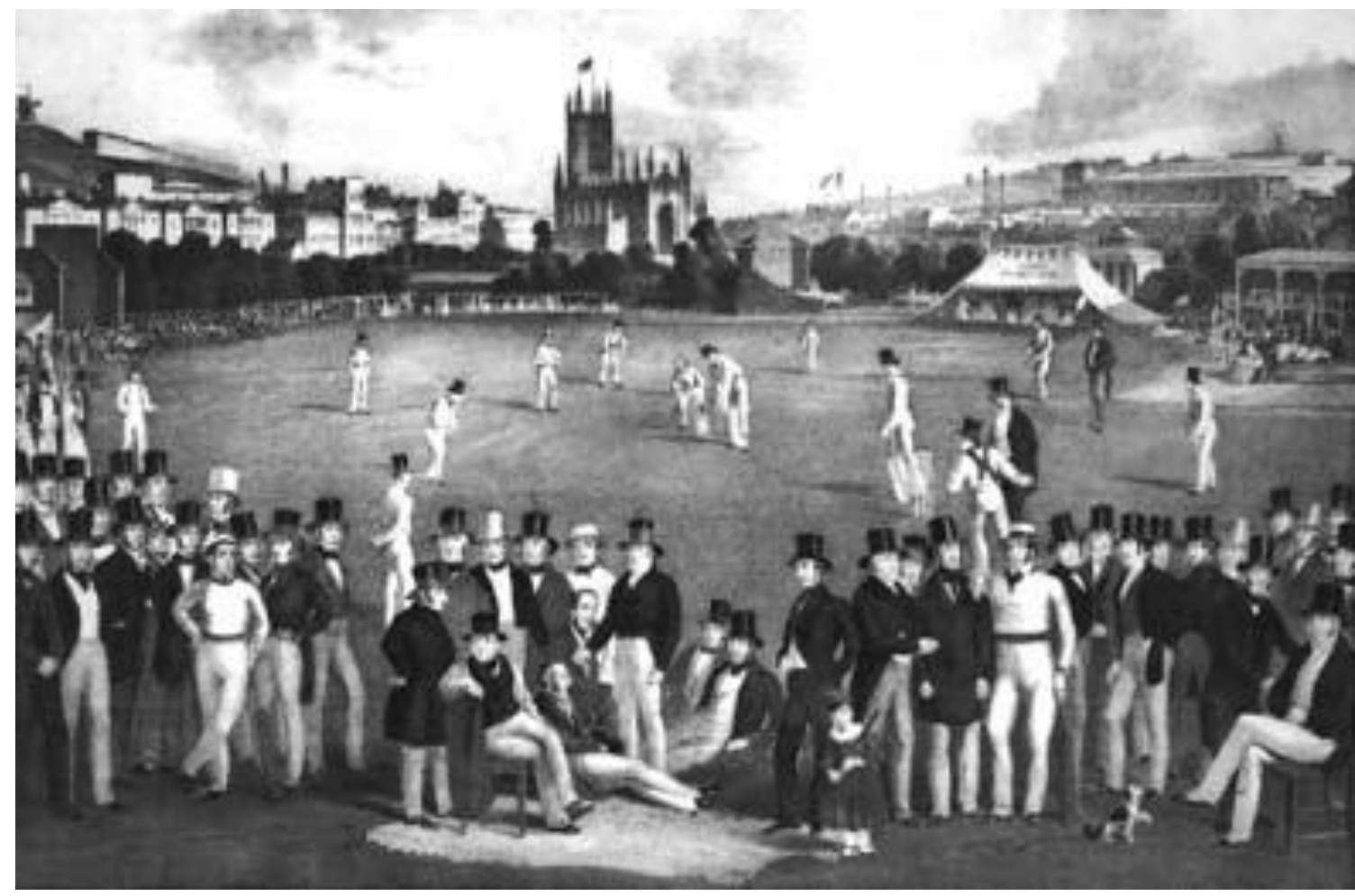

El fair play fue el lema del gentleman amateur. Antes de mediados del siglo XIX los términos «gentlemen» $\mathbf{y}$ «players» (jugadores) eran usados principalmente en el crícket, para diferenciar a los que tenían recursos independientes y aquellos que no. El grabado de S. Lipschitz de la imagen muestra un partido de cricket entre Sussex y Kent en Brighton en 1849.

\section{El decline del ethos amateur: de Eton a Proshow.}

La palabra amateur viene del verbo latino amare, que significa amar. Es por eso que se considera que los amateurs son aquellos atletas que solo juegan por el amor al juego. Sin embargo, amateurismo tuvo distintos significados. Fue parte de un «proceso de civilización» y de autocontrol,

\footnotetext{
${ }^{8}$ La práctica de tratar a ciertos atletas como amateurs para que sean elegibles para una competición amateur, mientras que en realidad se los «contrataba» mediante pagos ilegales.
} 
y al mismo tiempo, fue una forma de promocionar el espíritu de competencia por sí mismo. La hostilidad hacia las apuestas puso al deporte amateur en el campo de la ética de trabajo protestante y de la burguesía industrial, como opuesta a la aristocracia, que, con su código de honor preindustrial, continuaban apostando en las carreras de caballos, pero desaprobaban el pago de jugadores profesionales. Para este sector de la sociedad, pagar un salario a los jugadores arruinaba la diversión y vencía el propósito moral de los juegos, que consistía en mejorar el cuerpo y el carácter (Holt, 1992). ¿Dónde hemos escuchado esto antes? «Mens sana in corpore sano», lo que me lleva a preguntarme por qué los apologistas del deporte y la educación física olvidan citar la totalidad del enunciado del poeta romano Juvenal, quien en realidad dijo «Orandum est ut sit mens sana in corpore sano» (Satire, 10, p. 356), es decir, «Recemos para que haya una mente sana en un cuerpo sano». John Hulley, del Liverpool Athletic Club, usó la bien conocida frase abreviada en 1862 como motivo de las competiciones pertenecientes al Festival Olímpico de Liverpool, que desde entonces ha tenido una vida propia, como una perfecta ilustración de wishful thinking. El declive gradual del amateurismo en el deporte está bien documentado en el libro de D. J. Taylor titulado On the Corinthian spirit (2006).

En la Declaración de Fair Play del Internacional Council of Sport and Physical Education (ICSPE), publicada en la sede de la UNESCO de París en 1976, todavía puede leerse:

«Fair play... requiere como mínimo que [el competidor] demuestre un estricto e indefectible cumplimiento de la regla escrita [obligatoria], ... fair play es encarnado en la modestia en la victoria, y la elegancia en la derrota... El árbitro no debe confinar su participación al campo de juego. Será su mérito buscar generar contactos con los competidores, tanto antes como después de la competición» (citado por McIntosh, 1979, pp. 122-123).

Me temo qué si un árbitro hiciera esto hoy, seguramente sería despedido por su asociación. En contraste con esta visión más bien idealista, o debería decir «paternalista», de los deportes amateurs de los viejos tiempos, está el hecho de que los deportes con espectadores se han convertido en «(...) die wichtigste Nebensache del Welt» (la trivialidad más importante del mundo). Diez años antes de la abolición oficial de la regla amateur por parte del Movimiento Olímpico, Allen Guttmann escribió:

«La regla amateur era un instrumento de la lucha de clases..., el intento de limitar los deportes a los gentleean con recursos económicos aún sobrevive en el rol anacrónico del amateur [...]. Las naciones occidentales deben abolir la distinción amateur-profesional ya que hace tiempo se volvió anacrónica y porque está corroída por la hipocresía, mientras se burla la práctica en las naciones comunistas donde los amateurs dedican tanto tiempo a los deportes como lo hacen nuestros profesionales.»(Guttmann, A.,1978, pp. 31-32)

Mientras Guttmann imploró por renunciar al anacrónico e hipócrita estado amateur, Peter McIntosh (1979, p. 138) se mostró, desde un punto de vista más pedagógico, en contra de la profesionalización de los Juegos Olímpicos. Alegaba que mientras predicaban públicamente y promocionaban el humanismo, los ideales amateurs, la igualdad en términos de competición, la amistad en los certámenes y otros valores, cumplían con su lema «Citius, altius, fortius», contribuyendo a la profesionalización del deporte. McIntosh (1979, p. 139) se vio decepcionado por la retórica vacía del Movimiento Olímpico durante la Guerra Fría, en la que los términos amateurismo y fair play tenían connotaciones más absurdas que morales. Probablemente con gran arrepentimiento y dolor en su corazón, predijo la inevitable bifurcación en la que entró la Educación Física por un lado y el deporte, y su negocio, por otro. 
«A pesar de los importantes pronunciamientos sobre deporte por parte del Comité Olímpico Internacional, de la UNESCO y otros prestigiosos organismos, es posible que la moralidad del deporte no se preserve en los grandes encuentros deportivos, sino en los 'picados' con amigos».

Guttmann y McIntosh tuvieron en consecuencia muy diferentes puntos de vista acerca de la transformación del deporte de alto nivel en la industria del entretenimiento, cuando escribieron sus tesis a fines de la década de 1970. Mientras Guttmann actuó como un observador objetivo que vio el surgimiento de una industria del entretenimiento deportivo globalizada y profesionalizada (ver su libro Sports Spectators, 1986), McIntosh seguía manteniendo una lucha contra la pérdida del ethos amateur y del espíritu deportivo de fair play. Por lo tanto, ¿debería McIntosh ser considerado un inocente nostálgico del pasado, y por el otro lado, Guttmann un observador objetivo sin «compromiso» social? Creo que cada uno de ellos miraba diferentes tipos de deportes y desde diferentes perspectivas. El académico americano Allen Guttmann, inmerso en la novedosa escena deportiva «made in America», mostró un razonable acercamiento al mundo del espectáculo deportivo. Por su parte, el profesor de educación física británico, Peter McInstosh, estaba preocupado por la difícil tarea de la educación moral en relación con el deporte. Tal vez no diferenció lo suficiente entre la educación física a través del deporte, por un lado, y el deporte como negocio de entretenimiento por otro; posiblemente debido a que, en su país, la educación física (masculina) a través del deporte se utilizó como formador de los futuros «hombres de negocios».

Ya he señalado la gradual deportivización de la educación física en el continente europeo donde, antes de la década de 1960, la Gimnasia Sueca, la Gimnasia Alemana u otros sistemas similares dominaban los currículum escolares (Renson, 1999). Algunos han visto este desarrollo no como un «aggiornamento», sino como un fiasco educativo, o como concluyó Gilbert Andrieu (1992, p. 153): «La educación física está enferma porque se parece demasiado al deporte».

Desde el primer Congreso Olímpico en 1894, en el que el principio amateur era el tema central junto con el restablecimiento de los Juegos Olímpicos, el deporte y el Movimiento Olímpico han pasado por un proceso de cambios drásticos. Han migrado de «Eton a Proshow». Los deportes y juegos ya no son más exclusivos de las «clases de ocio», ya que el movimiento «Deporte para todos» (Sport for all) se ha esforzado en democratizar las actividades físicas para ambos sexos, todas las edades y clases sociales. El amateurismo, por otro lado, ha sido abandonado como el principio que guiaba el Movimiento Olímpico a partir de los Juegos de Seúl 1988, donde la escena deportiva cambia, ingresando en la misma los deportistas profesionales, convirtiéndose en un espectáculo profesional o «Proshow», en el que rigen otras reglas, muy diferentes a las utilizadas en los campos de juego de Eton.

\section{Conclusiones}

El deporte moderno se originó en Gran Bretaña como un producto cultural de la modernidad enfatizando la igualdad y la competencia. El fair play era el credo moral de este nuevo ethos deportivo. Guttmann (1985) consideró al fair play como un nuevo ethos caballeresco creado por la clase alta inglesa a mediados del siglo XIX. Mi tesis apunta a que el fair play fue defendido por la simple necesidad de sobrevivir a juegos rudos jugados entre pares. El francés Pierre de Coubertin, padre fundador del Movimiento Olímpico moderno, adoptó este producto cultural británico y lo utilizó como el principal cimiento de su pedagogía deportiva para, luego, difundirlo por todo el mundo. 
Sin embargo, el deporte no es educativo en sí mismo. Se convierte en educativo cuando se lo ubica en un contexto educativo (Renson, 2003). La pregunta, por lo tanto, es si puede o no ese contexto educativo volverse operacional en nuestras canchas deportivas y, en ese caso, dónde, cuándo y cómo.

Soy optimista en que la ética del fair play tiene un futuro en un entorno educativo bajo un liderazgo moral apropiado y probablemente también en un contexto más recreativo en el que «ganar no es lo único». Sin embargo, soy mucho menos optimista acerca de los cambios de la misma ética de fair play en contextos profesionales o semi profesionales, en los que ganar o perder se ve en términos económicos. Alexander Trollope ya criticó la creciente seriedad del deporte en 1868 al decir que «(...) una ocupación, para ser agradable, debería ser placentera y no un negocio» (pp. 67). George Orwell, que jugó para el equipo de futbol de Eton expresó su opinión sobre la seriedad de los deportes en términos más drásticos:

«El deporte serio no tiene nada que ver con el fair play. Está ligado al odio, a los celos, a la ostentación, a la indiferencia de todas las reglas y al placer sádico de ser testigo de la violencia, en otras palabras, es la guerra sin los disparos» (1945).

El gobierno corporativo, los derechos profesionales y las obligaciones en términos de legislación laboral deberían regir el deporte de alto nivel, garantizando así su carácter legal y la ética profesional. Durante mucho tiempo, el deporte serio no ha sido tomado lo suficientemente en serio.

La vox populi está pidiendo juegos y deportes más espectaculares y, al mismo tiempo, los y las deportistas están solicitando legítimamente su compromiso con el fair play. Por lo tanto, todos los interesados en la preservación de los valores morales del fair play en el deporte tendrán que afrontar algunos serios desafíos y responder algunas preguntas como, por ejemplo: juego?

¿Cómo podemos seguir jugando el juego por el juego mismo y no solo por la apuesta del

¿Cómo pueden los profesores de educación física hacerle frente al nuevo credo deportivo (o, mejor dicho, codicia deportiva)?

¿Cuándo el deporte profesional se convertirá en una rama independiente del mundo empresarial completamente desarrollada con un código de ética profesional, orientación profesional, etc., y como una institución autosuficiente?

¿El fair play se ha convertido en un sobreviviente anacrónico del viejo ideal amateur? ¿O el amateurismo debería reinventarse como propuso recientemente Lincoln Allison (2001)?

El fair play es una de las contribuciones más importantes que el deporte ha hecho a la ética moderna. Al observar los orígenes del concepto espero haber estimulado la reflexión postmoderna. Sin el fair play, el deporte, como todas las demás prácticas competitivas, se convertirían en una crítica sobre su relevancia para el movimiento cultural de la sociedad mera cuestión de ganar a toda costa, de hecho, ... la guerra sin los disparos. 


\section{Bibliografía}

- Allison, L. (2001). Amateurism and sport: an analysis and a defense. London: Frank Cass.

- Andrieu, G. (1992). Enjeux et débats en E.P.: une histoire contemporaine.s.l.. Actio.

- Ashworth, C.E. (1971). Sport as a symbolic dialogue. In E. Dunning (Ed), The sociology of sport: a selection of readings (pp. 40-46). London: Frank Cass. https://doi.org/10.3138/9781442654044-008

- Cavalini, R. (2007). Play up Corinth: a history of Corinthian Football Club 1882-1939. Stroud: The History Press. Collins, T., Martin, J., Vamplew, R. (Eds) (2005). Encyclopaedia of traditional British rural sports. London: Routledge.

- Crowley, M., \& Crowley, M. (1999). Spotlight on handicap, Take our word for it 66 (27 Dec; http://www.takeourword. com/issue 27.html)

- Demolins, E. (1897). A quoi tient la supériorité des Anglo-Saxons? Paris: Firmin- Didot.

- Dunning, E. (1971). The development of modern football. In E. Dunning (Ed), The sociology of sport: a selection of readings (pp. 133-151). London: Frank Cass. https://doi.org/10.3138/9781442654044-014

- Elias, N. (1971). The genesis of sport as a sociological problem. In E. Dunning (Ed), The sociology of sport: a selection of readings (pp. 88-115). London: Frank Cass. https://doi.org/10.3138/9781442654044-012

- Elias, N. (1986). An essay on sport and violence, In N. Elias \& E. Dunning, Quest for excitement: sport and leisure in the civilizing process (pp. 150-174). Oxford: Blackwell.

- Gillmeister, H. (1993). Not Cricket und Fair Play: Betrachtungen zum Englischen Sportgedanken. In V. Gerhardt \& M. Lämmer (Eds), Fairness und Fair Play (pp. 127-137). Sankt Augustin: Academia.

- Guttmann, A. (1987). From ritual to record: the nature of modern sport. New York: Columbia University Press.

- Guttmann, A. (1985). The belated birth and threatened death of fair play, The Yale Review, 74(Summer), 525-537.

- Guttmann, A. (1986). Sports spectators. New York: Columbia University Press. https://doi.org/10.7312/gutt06400

- Guttmann, A. (1988). A whole new ball game: an interpretation of American sports. Chapel Hill: The University of North Carolina Press.

- Guttmann, A. (2004). Sports: the first five millennia. Amherst: University of Massachusetts Press. 
- Holt, R. (1989). Sport and the British: a modern history. Oxford: Clarendon Press.

- Holt, R. (1992). Amateurism and its interpretations: the social origin of British sport. Innovation, 5(4), 19-31. https://doi.org/10.1080/13511610.1992.9968318

- Holt, R. (1992). The amateur body and the middle-class man: work, health and style in Victorian Britain. Sport in history, 26(3), 352-369. https://doi.org/10.1080/17460260601065953

- Hornby, H. (2008). Uppies and downies: the extraordinary football games of Britain. Swindon: English Heritage. Inglis, S. (2008). Forword. In H. Hornby, Uppies and downies: the extraordinary football games of Britain (p. 7). Swindon: English Heritage.

- Huizinga, J. (1938). Homo ludens: proeve eener bepaling van het spelelement der cultuur. Haarlem: Tjeenk-Willink.

- Indorf, H. (1938). Fair Play und der "Englische Sportgeist”. Hamburg: Friederichsen-de Gruyter.

- Johnson, P. (1977). Education of an establishment. In The world of the public school (pp. 3-28). London: Weidenfeld \& Nicolson.

- Kircher, R. (1927). Fair Play: Sport Spiel und Geist in England. Frankfurt am main: SocietasDruckerei.

- Loland, S. (2002). Fair play in sport: a modern norm system. London: Routledge.

- MacAloon, J.J. (1981). This great symbol: Pierre de Coubertin and the origins of the modern Olympic Games. Chicago: The University of Chicago Press.

- MacDonald Fraser, G. (1977). Manly little chaps. In The world of the public school (pp. 111123). London: Weidenfeld \& Nicolson.

- Mangan, J.A. (1981). Athleticism in the Victorian and Edwardian public school: the emergence of an educational ideology. Cambridge: Cambridge University Press.

- Mangan, J.A. (1998). The games ethic and imperialism: aspects of the diffusion of an ideal. London: Frank Cass.

- McIntosh, P. (1979). Fair play: ethics and sport in education. London: Heinemann.

- McKibbin, R. (1990). The ideologies of class: social relations in Britain 1880-1950. Oxford: Oxford University Press.

- Orwell, G. (1945). The sporting spirit, Tribune, 468 (14 Dec), 10-11.

- Oxford University Press (1989). Oxford English Dictionary. Oxford: Oxford University Press. 
- Renson, R. (1976). Juan Luis Vives (1492-1540) and the moral aspects of play. In J.P. Massicotte \& C. Lessard (Eds), Histoire, jeux et sports au Canada (1-18). Trois Rivières: Département d'Education Physique.

- Renson, R. (1980). Geschiedenis van de sport in de oudheid. Leuven: Acco.sépiRenson, R. (1999). Physical education in Europe from a cross-national perspective. In J.C. Bussard \& F. Roth (Eds), Which physical education for which school? (115-130). Bulle: Association Suisse d'Education Physique.

- Renson, R. (2003). Sport en opvoeding: een historische benadering. Olympic News magazine, (oct-nov-dec), 19-20.

- Sanders, A. (1989). Introduction. In T. Hughes, Tom Brown's schooldays (pp. VII-XXV). Oxford: Oxford University Press.

- Storr, A. (1977). The individual and the group, In The world of the public school (pp. 97-110). London: Weidenfeld \& Nicolson.

- Taylor, D.J. (2006). On the Corinthian spirit: the decline of amateurism in sport. London: Yellow Jersey Press. Ushborne, R. (1977). The shadow of Tom Brown, En The world of the public school (pp. 36-50). London: Weidenfeld \& Nicolson, 1977.

- Weiler, I. (1991). Regel und Regelbruch bei den antiken Olympischen Spielen. In R. Renson et.al. (Eds), The Olympic Games through the ages: Greek antiquity and its impact on modern sport (55-64). Athens: Hellenic Sports Research Institute.

- Wigglesworth, N. (1996). The evolution of English sport. London: Frank Cass. iLepiWillughby, F. (2003). Francis Willughby's book of games: a seventeenth century treatise on sports, games and pastimes (Ed. and introd. by D. Cram, J.L. Forgeng, D. Johnston). Aldershot: Ashgate. 